\section{Commentary: A giant step forward in valve care}

Pavan Atluri, MD, ${ }^{\mathrm{a}}$ and

John A. Elefteriades, MD, $\mathrm{PhD}$ (hon) ${ }^{\mathrm{b}}$

Video clip is available online.

The first installment from the European Association for Cardio-Thoracic Surgery/Society of Thoracic Surgeons/ American Association for Thoracic Surgery Valve Labeling Task Force (on which we served) focused on fundamental aspects in imaging and assessment of valvular heart disease and fundamentals of valve design and construction. The purpose was to set the stage for a later paper proposing a set of uniform criteria for description of manufactured prosthetic heart valves. This whole process arose out of frustration that nominal manufacturer valve sizes bore little relationship to physical characteristics and hemodynamic performance of the valves.

The current Task Force article, entitled "Essential Information on Surgical Heart Valve Characteristics for Optimal Valve Prosthesis Selection: Expert Consensus Document From the EACTS-STS-AATS Valve Labeling Task Force," is the end product of intense deliberations among surgeons, regulatory agencies, and industry partners. The culmination of this most recent effort is outlined in this article, which details the vital adjunctive information that the Task Force thinks would be most helpful and appropriate in aiding practicing cardiac surgeons to decide on the optimal valve

\footnotetext{
From the a Division of Cardiovascular Surgery, Department of Surgery, University of Pennsylvania, Philadelphia, Pa; and ${ }^{\mathrm{b}}$ Aortic Institute at Yale-New Haven Hospital, Yale University School of Medicine, New Haven, Conn.

Disclosures: Dr Elefteriades: Principal, CoolSpine; Consultant for CryoLife; Data/ Safety Monitoring Board for Terumo. Dr Atluri has reported no conflicts of interest.

The Journal policy requires editors and reviewers to disclose conflicts of interest and to decline handling or reviewing manuscripts for which they may have a conflict of interest. The editors and reviewers of this article have no conflicts of interest.

Received for publication Sept 3, 2020; revisions received Sept 3, 2020; accepted for publication Sept 3, 2020; available ahead of print Sept 10, 2020.

Address for reprints: John A. Elefteriades, MD, PhD (hon), Aortic Institute at YaleNew Haven, Yale University School of Medicine, 789 Howard Ave, Clinic Building CB 317, New Haven, CT 06519 (E-mail: john.elefteriades@yale.edu).

J Thorac Cardiovasc Surg 2021;161:559-62

$0022-5223 / \$ 36.00$

Copyright (C) 2020 by The American Association for Thoracic Surgery

https://doi.org/10.1016/j.jtcvs.2020.09.020
}

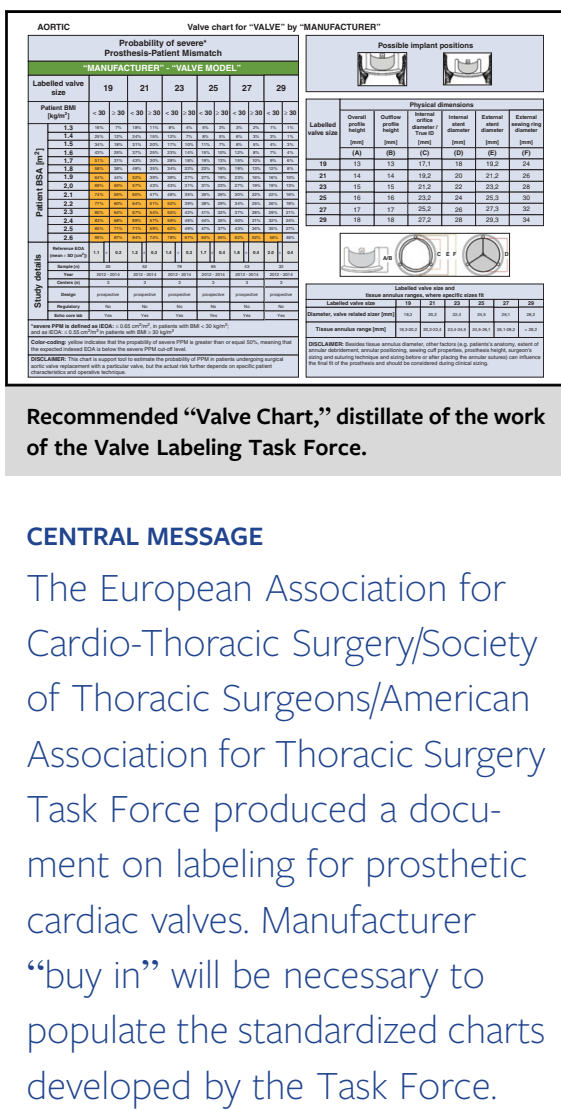

selection for their patients, in uniform format, in descriptive packaging of prosthetic heart valves from all manufacturers. The goal is to permit, expedite, and enhance informed, rational selection of the best valve for the patient currently on the operating table. It is fair to say that there has been a strong demand among surgeons for such accurate, ready-to-use, impartial information for many decades. We can attest that the chart representing the consensus set of required data was not achieved by the committee without considerable effort, discussion, and, yes, "vigorous" debate.

The Task Force document strongly encourages and emphasizes direct echocardiographic measurement of valve performance in patients (valve gradient and effective orifice area) over in vitro bench experiments and in vivo experiments in laboratory animals. The human data, the Task Force thinks, is more meaningful. Even that human data, they emphasize, vary on a traditional "bell curve" distribution, reflective of differences in intracardiac anatomy, inotropic state, and left ventricular function among human beings. Nonetheless, adjudicated and statistically collated data are thought to be to the benefit of clinicians.

The end product of the meetings and discussions by the Task Force is a recommended format for the "Valve Chart" 
(Figure 1) to be provided by each manufacturer for each of its valves. The Valve Chart includes (1) a pictogram of possible implant positions (relative to the annulus); (2) a chart of actual valve sizer diameters for each nominal size valve; and (3) a chart of the probability of severe patientprosthesis mismatch for each valve for patients with different body surface areas. Responsibility falls on our industry partners to formulate these charts, including additional clinical research, if necessary. The Valve Chart distillate of these Task Force efforts will constitute a discrete, substantive step forward in surgical care of patients with valvular heart disease.

Of course, the Task Force does not hold official authority in these matters. Rather, it is hoped that the effort, precision, and gravitas with which this process was carried out-with experts from cardiology, cardiac imaging, cardiac surgery, engineering, manufacturing, and key regulatory bodies-will induce voluntary and, hopefully, enthusiastic uniform compliance among manufacturers. The organizers of the Task Force had the wisdom to include, a priori, representatives from all major manufacturers and key regulatory bodies in the discussions. At the end, these industry partners were critical members in outlining feasibility and providing a path forward toward improving outcomes of our patients.

Most of the information will be readily available to manufacturers through their own engineering and clinical testing and regulatory requirements for Food and Drug Administration and international agency approval. However, it is possible that some additional testing may be required of the manufacturers, for hemodynamic data and patientprosthesis mismatch, for example. Can manufacturers "cherry-pick" the best data for these charts? Of course, but the playing field should, in theory, be level. The committee members thought that requiring hemodynamic data on a minimum of 30 patients per valve per size was reasonable, permitting reliable average measurements without excessive investigational burden.

Some surgeons may be disappointed that the Task Force did not recommend a uniform set of sizers suitable for all valves.
AORTIC

\begin{tabular}{|c|c|c|c|c|c|c|c|c|c|c|c|c|c|}
\hline \multicolumn{14}{|c|}{$\begin{array}{l}\text { Probability of severe* } \\
\text { Prosthesis-Patient Mismatch }\end{array}$} \\
\hline \multicolumn{14}{|c|}{ “MANUFACTURER" - “VALVE MODEL" } \\
\hline \multirow{2}{*}{\multicolumn{2}{|c|}{$\begin{array}{c}\begin{array}{c}\text { Labelled valve } \\
\text { size }\end{array} \\
\begin{array}{c}\text { Patient BMI } \\
{\left[\mathrm{kg} / \mathrm{m}^{2}\right]}\end{array}\end{array}$}} & \multicolumn{2}{|c|}{19} & \multicolumn{2}{|c|}{21} & \multicolumn{2}{|c|}{23} & \multicolumn{2}{|c|}{25} & \multicolumn{2}{|c|}{27} & \multicolumn{2}{|c|}{29} \\
\hline & & $<30$ & $\geq \mathbf{3 0}$ & $<30$ & $\geq 30$ & $<30$ & $\geq \mathbf{3 0}$ & $<30$ & $\geq \mathbf{3 0}$ & $<30$ & $\geq \mathbf{3 0}$ & $<30$ & $\geq \mathbf{3 0}$ \\
\hline \multirow{14}{*}{ 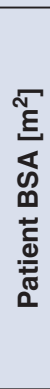 } & 1.3 & $16 \%$ & $7 \%$ & $18 \%$ & $11 \%$ & $8 \%$ & $4 \%$ & $5 \%$ & $3 \%$ & $3 \%$ & $2 \%$ & $1 \%$ & $1 \%$ \\
\hline & 1.4 & $25 \%$ & $12 \%$ & $24 \%$ & $15 \%$ & $12 \%$ & $7 \%$ & $8 \%$ & $5 \%$ & $6 \%$ & $3 \%$ & $3 \%$ & $1 \%$ \\
\hline & 1.5 & $34 \%$ & $18 \%$ & \begin{tabular}{|l|}
$31 \%$ \\
\end{tabular} & $20 \%$ & $17 \%$ & $10 \%$ & \begin{tabular}{|l|}
$11 \%$ \\
\end{tabular} & $7 \%$ & $8 \%$ & $5 \%$ & $4 \%$ & $3 \%$ \\
\hline & 1.6 & $43 \%$ & $25 \%$ & \begin{tabular}{|l|}
$37 \%$ \\
\end{tabular} & \begin{tabular}{|l|}
$25 \%$ \\
\end{tabular} & $23 \%$ & $14 \%$ & \begin{tabular}{|l|}
$15 \%$ \\
\end{tabular} & $10 \%$ & \begin{tabular}{|l|l|}
$12 \%$ \\
\end{tabular} & $8 \%$ & $7 \%$ & $4 \%$ \\
\hline & 1.7 & $51 \%$ & $31 \%$ & \begin{tabular}{|l|}
$43 \%$ \\
\end{tabular} & $30 \%$ & $28 \%$ & $18 \%$ & \begin{tabular}{|l|}
$19 \%$ \\
\end{tabular} & \begin{tabular}{|l|}
$13 \%$ \\
\end{tabular} & $15 \%$ & \begin{tabular}{|l|}
$10 \%$ \\
\end{tabular} & $9 \%$ & $6 \%$ \\
\hline & 1.8 & $58 \%$ & $38 \%$ & \begin{tabular}{|l|l|}
$48 \%$ \\
\end{tabular} & $35 \%$ & $34 \%$ & $22 \%$ & $23 \%$ & $16 \%$ & \begin{tabular}{|l|l|}
$19 \%$ \\
\end{tabular} & $13 \%$ & $12 \%$ & $8 \%$ \\
\hline & 1.9 & $64 \%$ & $44 \%$ & \begin{tabular}{|l|l|}
$52 \%$ \\
\end{tabular} & $39 \%$ & $39 \%$ & $27 \%$ & \begin{tabular}{|l|}
$27 \%$ \\
\end{tabular} & \begin{tabular}{|l|}
$19 \%$ \\
\end{tabular} & \begin{tabular}{|l|}
$23 \%$ \\
\end{tabular} & \begin{tabular}{|l|}
$16 \%$ \\
\end{tabular} & \begin{tabular}{|l|l|}
$16 \%$ \\
\end{tabular} & $10 \%$ \\
\hline & 2,0 & $69 \%$ & $50 \%$ & \begin{tabular}{|l|}
$57 \%$ \\
\end{tabular} & \begin{tabular}{|l|}
$43 \%$ \\
\end{tabular} & $43 \%$ & \begin{tabular}{|l|}
$31 \%$ \\
\end{tabular} & \begin{tabular}{|l|l|}
$31 \%$ \\
\end{tabular} & $23 \%$ & $27 \%$ & \begin{tabular}{|l|}
$19 \%$ \\
\end{tabular} & \begin{tabular}{|l|l|}
$19 \%$ \\
\end{tabular} & $13 \%$ \\
\hline & 2.1 & $74 \%$ & $55 \%$ & \begin{tabular}{|l|l|}
$60 \%$ \\
\end{tabular} & \begin{tabular}{|l|}
$47 \%$ \\
\end{tabular} & $48 \%$ & $35 \%$ & \begin{tabular}{|l|l|}
$35 \%$ \\
\end{tabular} & \begin{tabular}{|l|}
$26 \%$ \\
\end{tabular} & $30 \%$ & \begin{tabular}{|l|}
$22 \%$ \\
\end{tabular} & $22 \%$ & $16 \%$ \\
\hline & 2.2 & $77 \%$ & $60 \%$ & \begin{tabular}{|l|l|}
$64 \%$ \\
\end{tabular} & $51 \%$ & $52 \%$ & $39 \%$ & $38 \%$ & $29 \%$ & $34 \%$ & $25 \%$ & $26 \%$ & $18 \%$ \\
\hline & 2.3 & $80 \%$ & $64 \%$ & \begin{tabular}{|l|}
$67 \%$ \\
\end{tabular} & \begin{tabular}{|l|}
$54 \%$ \\
\end{tabular} & $55 \%$ & $42 \%$ & $41 \%$ & $32 \%$ & $37 \%$ & $28 \%$ & $29 \%$ & $21 \%$ \\
\hline & 2.4 & $83 \%$ & $68 \%$ & $69 \%$ & \begin{tabular}{|l|}
$57 \%$ \\
\end{tabular} & $59 \%$ & $46 \%$ & $44 \%$ & \begin{tabular}{|l|}
$35 \%$ \\
\end{tabular} & $40 \%$ & $31 \%$ & $32 \%$ & $24 \%$ \\
\hline & 2.5 & $85 \%$ & $71 \%$ & $71 \%$ & \begin{tabular}{|l|}
$59 \%$ \\
\end{tabular} & $62 \%$ & $49 \%$ & $47 \%$ & \begin{tabular}{|l|}
$37 \%$ \\
\end{tabular} & $43 \%$ & \begin{tabular}{|l|}
$34 \%$ \\
\end{tabular} & $35 \%$ & $27 \%$ \\
\hline & 2.6 & $95 \%$ & $87 \%$ & \begin{tabular}{|l|l|}
$84 \%$ \\
\end{tabular} & \begin{tabular}{|l|}
$74 \%$ \\
\end{tabular} & $78 \%$ & $67 \%$ & $64 \%$ & \begin{tabular}{|l|}
$55 \%$ \\
\end{tabular} & \begin{tabular}{|l|}
$62 \%$ \\
\end{tabular} & \begin{tabular}{|l|}
$52 \%$ \\
\end{tabular} & \begin{tabular}{|l|l|}
$56 \%$ \\
\end{tabular} & \begin{tabular}{|l|}
$46 \%$ \\
\end{tabular} \\
\hline \multirow{7}{*}{$\begin{array}{l}\frac{\infty}{\bar{T}} \\
\frac{\pi}{0} \\
\frac{0}{0} \\
\frac{7}{\partial} \\
\text { क }\end{array}$} & $\begin{array}{c}\text { Reference EOA } \\
\left(\text { mean } \pm \text { SD }\left[\mathrm{cm}^{2}\right]\right)\end{array}$ & 1.1 & 0.2 & 1.2 & 0.3 & 1.4 & 0.3 & 1.7 & 0.4 & 1.8 & 0.4 & 2.0 & 0.4 \\
\hline & Sample (n) & & & 52 & & 79 & & $\omega_{65}$ & & 43 & & $\begin{array}{ll}11 \\
32\end{array}$ & $\frac{1}{32}$ \\
\hline & Year & & 2014 & $2012-4$ & 2014 & 2012 - & 2014 & 2012 . & 2014 & $2012-$ & 2014 & 2012 - & -2014 \\
\hline & Centers $(n)$ & & 3 & 3 & & 3 & & 3 & & 3 & & 3 & 3 \\
\hline & Design & & ective & prospe & ective & prospe & ective & prospe & ective & prospe & ective & prospe & eective \\
\hline & Regulatory & & 10 & No & & $\mathrm{N}$ & & N & & No & & No & vo \\
\hline & Echo core lab & & & & & & & $\mathrm{Ye}_{\mathrm{Se}}$ & & $y_{e}$ & & $\mathrm{Ye}_{\mathrm{e}}$ & es \\
\hline \multicolumn{14}{|c|}{$\begin{array}{l}\text { "severe PPM is defined as iEOA: } \leq 0.65 \mathrm{~cm}^{2} / \mathrm{m}^{2} \text {, in patients with } \mathrm{BMI}<30 \mathrm{~kg} / \mathrm{m}^{2} \text {; } \\
\text { and as iEOA: } \leq 0.55 \mathrm{~cm}^{2} / \mathrm{m}^{2} \text { in patients with } \mathrm{BMI} \geq 30 \mathrm{~kg} / \mathrm{m}^{2}\end{array}$} \\
\hline \multicolumn{14}{|c|}{$\begin{array}{l}\text { Color-coding: yellow indicates that the propability of severe PPM is greater than or equal } 50 \% \text {, meaning that } \\
\text { the expected indexed EOA is below the severe PPM cut-off level. }\end{array}$} \\
\hline \multicolumn{14}{|c|}{$\begin{array}{l}\text { DISCLAIMER: This chart is support tool to estimate the probability of PPM in patients undergoing surgical } \\
\text { aortic valve replacement with a particular valve, but the actual risk further depends on specific patient } \\
\text { characteristics and operative technique. }\end{array}$} \\
\hline
\end{tabular}

Valve chart for "VALVE" by "MANUFACTURER"

\begin{tabular}{|c|c|c|c|c|c|c|}
\hline \multicolumn{7}{|c|}{ Possible implant positions } \\
\hline \multirow{3}{*}{$\begin{array}{l}\text { Labelled } \\
\text { valve size }\end{array}$} & \multicolumn{6}{|c|}{ Physical dimensions } \\
\hline & $\begin{array}{c}\begin{array}{c}\text { Overall } \\
\text { profile } \\
\text { height }\end{array} \\
{[\mathrm{mm}]}\end{array}$ & $\begin{array}{c}\begin{array}{c}\text { Outflow } \\
\text { profile } \\
\text { height }\end{array} \\
{[\mathrm{mm}]}\end{array}$ & 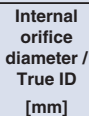 & $\begin{array}{c}\begin{array}{c}\text { Internal } \\
\text { stent } \\
\text { diameter } \\
\text { [mm] }\end{array} \\
\text { [mm }\end{array}$ & $\begin{array}{c}\begin{array}{c}\text { External } \\
\text { stent } \\
\text { diameter }\end{array} \\
{[\mathrm{mm}]}\end{array}$ & $\begin{array}{c}\begin{array}{c}\text { External } \\
\text { sewing ring } \\
\text { diameter }\end{array} \\
{[\mathrm{mm}]}\end{array}$ \\
\hline & (A) & (B) & (C) & (D) & (E) & (F) \\
\hline 19 & 13 & 13 & 17,1 & 18 & 19,2 & 24 \\
\hline 21 & 14 & 14 & 19,2 & 20 & 21,2 & 26 \\
\hline 23 & 15 & 15 & 21,2 & 22 & 23,2 & 28 \\
\hline 25 & 16 & 16 & 23,2 & 24 & 25,3 & 30 \\
\hline 27 & 17 & 17 & 25,2 & 26 & 27,3 & 32 \\
\hline 29 & 18 & 18 & 27,2 & 28 & 29,3 & 34 \\
\hline
\end{tabular}
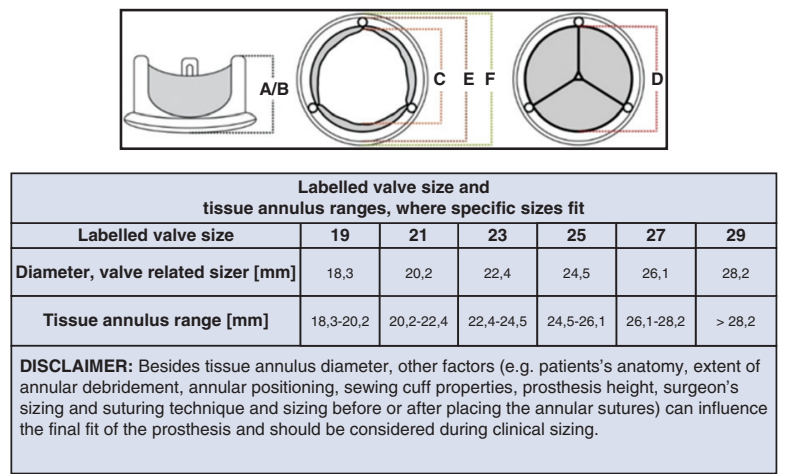

FIGURE 1. Recommended valve chart. Distillate of the work of the Task Force, providing the surgeon detailed information on the physical and performance characteristics of each valve, and the individual patient's likelihood of patient-prosthesis mismatch. Fictitious sample valve shown. BMI, Body mass index; $B S A$, body surface area; $E O A$, effective orifice area; $S D$, standard deviation; $P P M$, patient-prosthesis mismatch. Reprinted with permission from Durko and colleagues. ${ }^{1}$ 

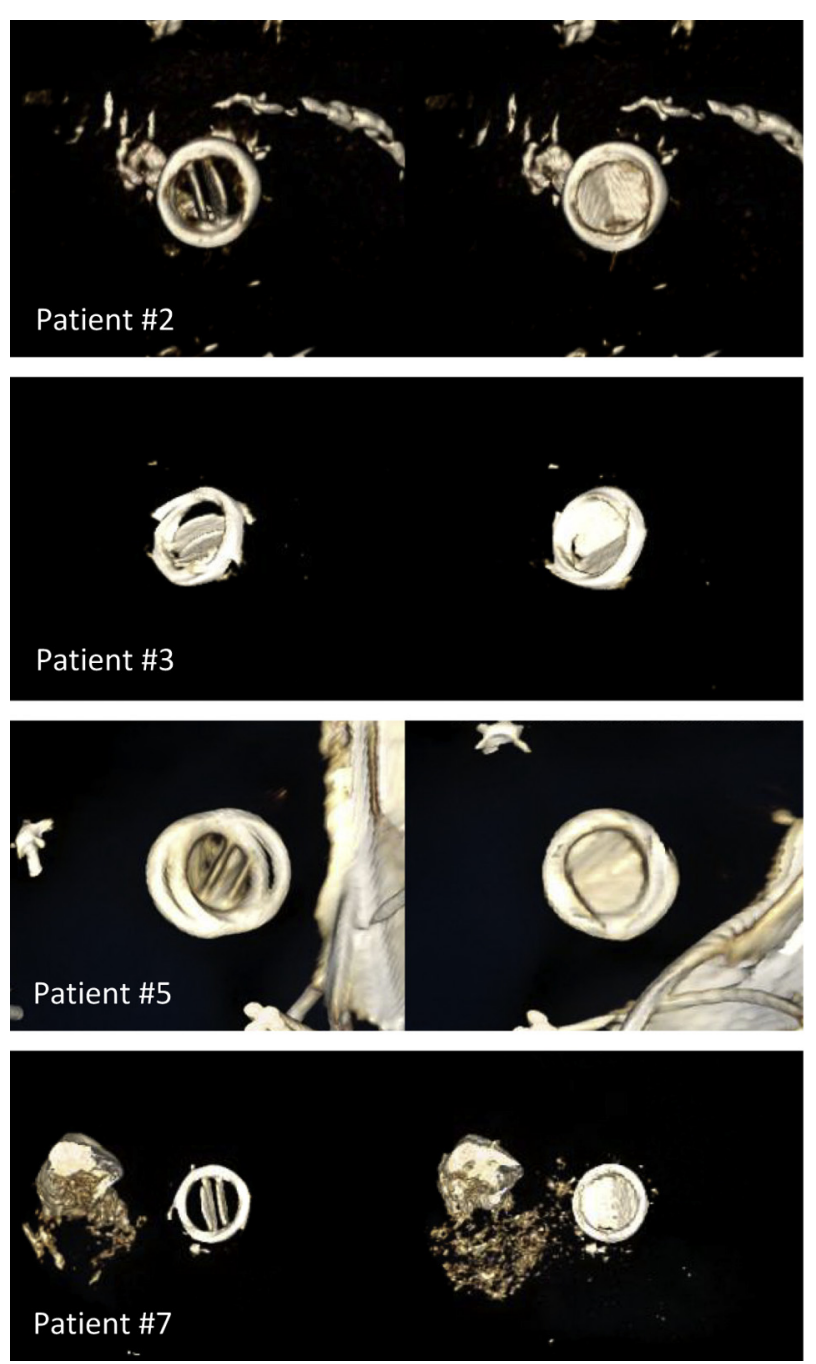
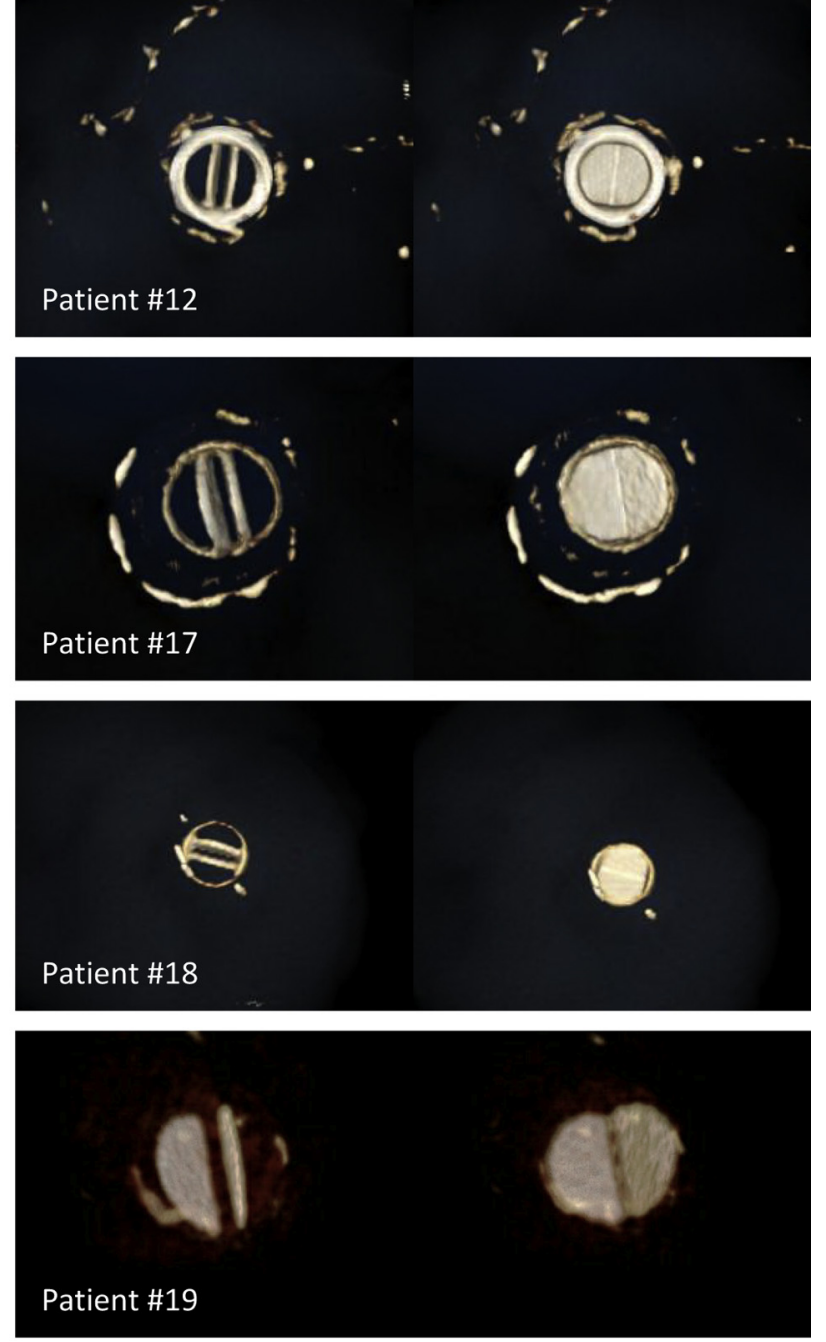

FIGURE 2. Three-dimensional reconstructed cine-CT images of mechanical aortic valves in systole and diastole, demonstrating full opening and closing of the bileaflet valve, except in number 19, where decreased excursion of 1 leaflet is seen. Reprinted with permission from Hsu and colleagues. ${ }^{2}$

This was discussed but considered impractical from the point of view of expense and development effort; furthermore, the physical designs and 3-dimensional shapes of valves differ so markedly that a uniform sizer would not be accurately representative and may hinder the ultimate valve implant.

Some surgeons may worry that the charts and inherent recommendations will limit their freedom in valve selection. The hope of the Task Force is to make the surgeon's work not more constricted, but rather easier and more secure. There will always be room for exercise of the art of surgery, which is where the true satisfaction of surgery arises. It is the hope of our Task Force that the considerable work that has been set forth will improve the experience for surgeons and enhance the short- and long-term outcomes of our patients.

We do take this opportunity to call to our readers' attention a new tool in the diagnostic armamentarium for

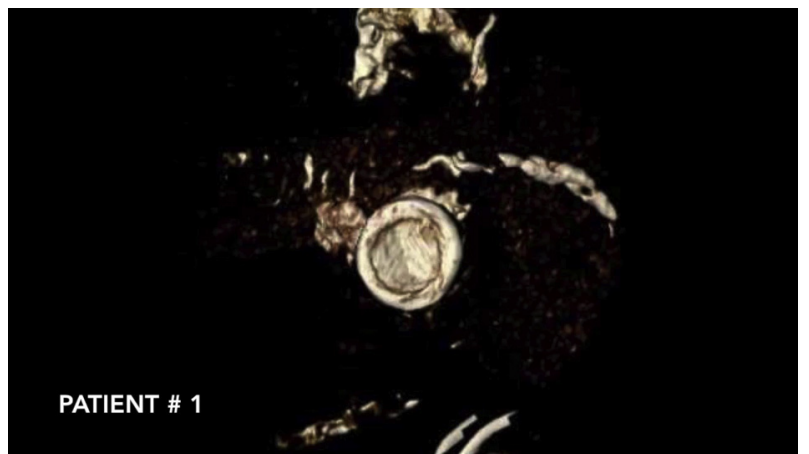

VIDEO 1. Cine-CT clips of mechanical aortic valves in systole and diastole demonstrating full opening and closing of bileaflet valve. Reproduced with permission from Hsu and colleagues. ${ }^{2}$ Video available at: https:// www.jtcvs.org/article/S0022-5223(20)32592-7/fulltext. 
assessment of suspected postoperative patient-prosthesis mismatch. We recently reported our experience with the modality of cine-computed tomography (CT) imaging, essentially moving pictures of the valve in motion. ${ }^{2}$ This technique allows unprecedented precision in imaging the valve and its leaflet motion. The cine-CT gives the sensation of almost "being there," inside the heart, watching the valve work in real time (Figure 2 and Video 1). Cine-CT easily detects thrombus, pannus, and restricted leaflet motion with great accuracy and resolution. In our recent report, we found that many cases of late-onset suspected patient-prosthesis mismatch could be traced to an increase in a patient's weight over years postimplant, placing an increased circulatory burden on a properly functioning valve.

\section{References}

1. Durko AP, Pibarot P, Alturi P, Bapat V, Cameron DE, Casselman FPA, et al. Essential information on surgical heart valve characteristics for optimal valve prosthesis selection: expert consensus document from the European Association for CardioThoracic Surgery (EACTS)-The Society of Thoracic Surgeons (STS)-American Association for Thoracic Surgery (AATS) Valve Labelling Task Force. J Thorac Cardiovasc Surg. 2021;161:545-58.

2. Hsu C, Bourganos K, Zafar MA, Huber S, Buntin J, Ziganshin BA, et al. Cine-computed tomography for the evaluation of prosthetic heart valve function. Cardiology. 2020;145:439-45.
See Article page 545.

\section{Commentary: Valve Labeling Task Force: Efforts now needed by manufacturers and surgeons}

\author{
John A. Elefteriades, MD, PhD (hon), ${ }^{a}$ and \\ Pavan Atluri, MD
}

Now that the 2 position articles of the European Association for Cardio-Thoracic Surgery, American Association for Thoracic Surgery, Society of Thoracic Surgeons Task Force on Valve Labeling have been published, ${ }^{1,2}$ we find ourselves on the threshold of reaping the benefits of these extensive deliberations. However, we are in the red zone but not across the goal line.

The focus of the joint American Association for Thoracic Surgery, European Association for Cardio-Thoracic Surgery, Society of Thoracic Surgeons Valve Labeling Task Force has been on uniformity of labeling with regard to dimensions, size, and hemodynamic performance. This

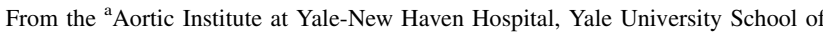
Medicine, New Haven, Conn; and ${ }^{\mathrm{b}}$ Division of Cardiovascular Surgery, Department of Surgery, University of Pennsylvania, Philadelphia, Pa.

Disclosures: J.A.E.: Principal, CoolSpine; Consultant for CryoLife; Data/Safety Monitoring Board for Terumo. P.A. reported no conflicts of interest.

The Journal policy requires editors and reviewers to disclose conflicts of interest and to decline handling or reviewing manuscripts for which they may have a conflict of interest. The editors and reviewers of this article have no conflicts of interest.

Received for publication Oct 16, 2020; revisions received Nov 2, 2020; accepted for publication Nov 13, 2020; available ahead of print Nov 19, 2020.

Address for reprints: John A. Elefteriades, MD, PhD (hon), Aortic Institute at YaleNew Haven, Yale University School of Medicine, 789 Howard Ave, Clinic Building CB 317, New Haven, CT 06519 (E-mail: john.elefteriades@yale.edu).

J Thorac Cardiovasc Surg 2021;161:562-4

$0022-5223 / \$ 36.00$

Copyright (c) 2020 by The American Association for Thoracic Surgery

https://doi.org/10.1016/j.jtcvs.2020.11.015

\section{Check for updates}

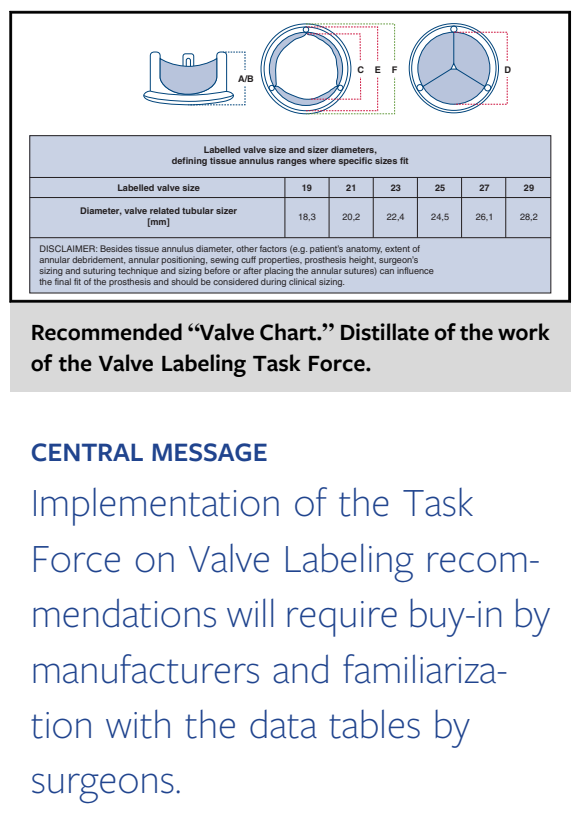

second follow-up article ${ }^{2}$ lays out the outcomes and decisions of the task force that will further aid surgeons in optimal valve selection with a clear elucidation of valve dimensions and hemodynamic performance.

Two further steps are needed before benefits of these efforts translate to surgeons and their patients. 